\title{
El control jurisdiccional de la actuación de los órganos forales de los Territorios Históricos del País Vasco. Últimos criterios jurisprudenciales en la materia
}

\author{
Carlos Romero Rey \\ Letrado del Tribunal Supremo
}

Recibido: 05.10 .07

Aceptado: 04.12.07

\begin{abstract}
Resumen: Las controversias suscitadas en torno a la naturaleza jurídica, caracterización y régimen competencial de los Territorios Históricos del País Vasco ha trascendido el puro debate doctrinal para trasladarse a instancias jurisdiccionales. El presente estudio analizará el complejo reparto competencial que se opera entre las instituciones comunes de la Comunidad Autónoma y los órganos forales de los Territorios Históricos, la función de la Comisión Arbitral para dirimir conflictos y la naturaleza jurídica de las normas dictadas por las Juntas Generales de los Territorios Históricos y si éstas gozan o no del valor de ley. Finalmente, se hará especial énfasis en la competencia objetiva de los órganos de la jurisdicción contencioso-administrativa para conocer de los recursos que se deduzcan contra actuaciones de los órganos forales de los Territorios Históricos.
\end{abstract}

Palabras clave: Territorios Históricos, Comisión Arbitral, Norma foral, Reparto de competencias.

Abstract: The controversy about the legal nature, characteristics and competences of the Territorios Históricos of the Basque Country has moved from the pure doctrinal debate towards the Courts arena. This study will deal with the complex division of competences inside the Basque Country government framework and the legal nature of the law enacted by the Juntas Generales. Finally, it will focus on the mandatory jurisdiction of the administrative courts to solve the disputes dealing with the legal acts of the Territorios Históricos.

Key words: Territorios Históricos, Arbitral Commission, Norma foral, Division of competences.

Sumario: I. Introducción.--II. La compleja naturaleza jurídica de los Territorios Históricos.-III. La Comisión Arbitral.-IV. Órganos Forales. 1. Juntas Generales. Naturaleza jurídica de las normas dictadas por las Juntas Generales. 2. Diputaciones Forales.

\section{INTRODUCCIÓN}

En los últimos tiempos, las controversias suscitadas en torno a la naturaleza jurídica, caracterización y régimen competencial de los Territorios His- 
tóricos del País Vasco ha trascendido el puro debate doctrinal para trasladarse a instancias jurisdiccionales.

Trataremos de suscitar en este estudio algunas de las cuestiones más polémicas en la materia, en cuanto puedan afectar a la forma en que ha de ejercitarse la fiscalización jurisdiccional de la actuación de los órganos forales de los Territorios Históricos del País Vasco, e igualmente trataremos de poner de manifiesto los últimos criterios jurisprudenciales elaborados al respecto.

Varios son los aspectos sobre los que nos vamos a detener, entre otros, el complejo reparto competencial que se opera entre las instituciones comunes de la Comunidad Autónoma y los órganos forales de los Territorios Históricos y la propia arquitectura competencial de estos últimos con la previsión de una Comisión Arbitral para dirimir conflictos, o la naturaleza jurídica de las normas dictadas por las Juntas Generales de los Territorios Históricos y si éstas gozan o no del valor de ley.

Ahora bien, centraremos nuestra atención especialmente en la competencia objetiva de los órganos de la jurisdicción contencioso-administrativa para conocer de los recursos que se deduzcan contra actuaciones de los órganos forales de los Territorios Históricos.

Para entender la complejidad jurídica de esta última cuestión, hemos de partir de la disposición adicional primera, apartado primero, de la Ley 29/1998, de 13 de julio, Reguladora de la Jurisdicción Contencioso-Administrativa, que señala lo siguiente:

«En la Comunidad Autónoma del País Vasco, la referencia del apartado 2 del artículo 1 de esta Ley incluye las Diputaciones Forales y la Administración Institucional de ellas dependiente. Asimismo, la referencia del apartado 3, letra a) del artículo 1 incluye los actos y disposiciones en materia de personal y gestión patrimonial sujetos al derecho público adoptados por los órganos competentes de las Juntas Generales de los Territorios Históricos».

El artículo 1 de la Ley Jurisdiccional se refiere al ámbito del orden jurisdiccional contencioso-administrativo; el apartado segundo, al que se refiere la disposición adicional antes aludida, dispone que se entenderá, a estos efectos, por Administraciones públicas:

a) la Administración General del Estado.

b) Las Administraciones de las Comunidades Autónomas.

c) Las Entidades que integran la Administración local.

d) Las Entidades de Derecho público que sean dependientes o estén vinculadas al Estado, las Comunidades Autónomas o las Entidades locales.

La cuestión de a cuál o a cuáles de los órganos de la jurisdicción contencioso-administrativa corresponde la fiscalización de los actos y disposicio- 
nes emanados por los órganos de los Territorios Forales se complica porque ni la disposición adicional primera aclara en cuál de los apartados del artículo 1.2 habrían de entenderse por analogía incluidos los órganos de los Territorios Históricos ni, por otra parte, los artículos de la Ley procesal que llevan a cabo la delimitación de competencias entre los distintos órganos, a saber, artículo 8, relativo a los Juzgados de lo Contencioso-Administrativo; artículo 9, relativo a los Juzgados Centrales; artículo 10, Salas correspondientes de los Tribunales Superiores de Justicia; artículo 11, Sala de lo Contencioso-Administrativo de la Audiencia Nacional y artículo 12, Sala de lo Contencioso-Administrativo del Tribunal Supremo, tampoco se refieren en ninguno de sus apartados a los actos y disposiciones emanados de los Territorios Históricos.

Por ello, la determinación de la competencia objetiva para el conocimiento de la actuación de los órganos forales de los Territorios Históricos del País Vasco requiere, ante la falta de una regla de atribución en la Ley Jurisdiccional, realizar una aproximación a la naturaleza jurídica de éstos.

\section{LA COMPLEJA NATURALEZA JURÍDICA DE LOS TERRI- TORIOS HISTÓRICOS}

La Constitución Española de 1978 señala en su disposición adicional primera $^{1}$ que «La Constitución ampara y respeta los derechos históricos de los territorios forales», al tiempo que dispone seguidamente que «La actualización general de dicho régimen foral se llevará a cabo, en su caso, en el marco de la Constitución y de los Estatutos de Autonomía».

Respecto de tal previsión, el Tribunal Constitucional, en Sentencia 140/1990, de 20 de septiembre, señaló que los dos párrafos de dicha disposición adicional primera requieren una lectura conjunta, de la que se deduce que la garantía institucional del régimen foral que se establece en el primer párrafo se vincula a la actualización de los derechos históricos que se efectúa por el Estatuto de Autonomía en el marco de la Constitución.

Por consiguiente, va a ser el Estatuto el elemento decisivo de la actualización de los derechos históricos. La citada Sentencia asimismo acepta que la disposición adicional primera antes citada constituye un título autónomo de asunción de competencias.

A la garantía institucional de la foralidad se refiere, por su parte, la Sentencia del Tribunal Constitucional 159/1993, de 6 de mayo, que señala que «la garantía institucional de los territorios forales, si bien no especifica exhaustivamente las competencias históricas que protege (esto es, un haz

${ }^{1}$ El Título VIII de la Constitución («De la Organización Territorial del Estado) no hace referencia alguna a los Territorios Históricos. 
determinado de competencias concretas), sí alcanza, como mínimo irreductible, a proteger un régimen de autogobierno territorial con el que quepa reconocer el régimen foral tradicional de los distintos territorios históricos. (...) Dentro de estos límites, es al proceso de actualización previsto en la disposición adicional primera de la Constitución al que corresponde precisar cuál es el contenido concreto que, en el nuevo marco constitucional y estatutario, se da al régimen foral de cada uno de los citados territorios».

$\mathrm{Si}$ bien en un primer momento la doctrina consideró a los Territorios Históricos como meros entes locales, con las consecuencias que dicha consideración tenía desde la perspectiva de la naturaleza de sus normas jurídicas, progresivamente se fue planteando la «doble naturaleza jurídica de los Territorios Históricos» ${ }^{2}$. En cualquier caso, la doctrina ha mostrado un eclecticismo en cuanto a sus posiciones que da buena cuenta de la «peculiaridad» del régimen foral ${ }^{3}$.

Se ha considerado que las consecuencias de esa «naturaleza jurídica dual» de los Territorios Históricos tienen reflejo en las materias que regulan y en la naturaleza jurídica de las normas forales. Por su parte, la organización de los Territorios Históricos también se beneficia de su naturaleza jurídica foral al superar las formas de organización corporativa, estructurándose como regímenes parlamentarios, con un órgano representativo elegido directamente, las Juntas Generales, titulares de la potestad normativa y de la competencia para elegir al Diputado general, aprobar los presupuestos y controlar la acción de la Diputación Foral, y un órgano ejecutivo, la Diputación Foral, emanación de esas Juntas Generales, órgano colegiado que asume el gobierno y la administración, correspondiéndole la función ejecutiva, la potestad reglamentaria y la iniciativa normativa. La Diputación Foral, cuyos órganos cabecera son el Consejo de Diputados, el Diputado General y los Diputados Forales, es una administración burocrática totalmente parangonable a sus homónimas autonómica y estatal ${ }^{4}$.

2 I. LASAgABASTER Herrarte, «Los Consejos Insulares y los Territorios Históricos: un análisis comparado», Revista Vasca de Administración Pública, número 66, 2003, págs. 214 y ss.

${ }^{3}$ Como ya hemos dicho, la variedad de posicionamientos en cuanto a la naturaleza jurídica de los Territorios Históricos resulta difícilmente reconducible a la unidad. Resulta significativa, en este sentido, la posición de L. ElíCEGUI, «Las Instituciones Forales», en Estudios sobre el Estatuto de Autonomía del País Vasco, 1991, pág. 1471, quien considera los Territorios Históricos no como meras provincias, pero tampoco como Comunidades Autónomas uniprovinciales, aunque los sitúa más cerca de éstas que de aquéllas «por su contenido competencial y como poderes políticos de la Comunidad Autónoma del País Vasco», optando por considerarlos como «Instituciones pecualiares y cualquier esfuerzo de reducirlos a una cosa u otra llevará, a mi entender, a un resultado confuso, sin capacidad para resolver las múltiples cuestiones que se plantean».

${ }^{4}$ I. LASAgabaster HerRarte, «Los Consejos Insulares y los Territorios Históricos...», ob. cit., págs. 222 y ss. 
En este contexto, el Estatuto de Autonomía del País Vasco (Ley Orgánica 3/1979, de 18 de diciembre), dentro del Título II «De los poderes del País Vasco», va a dedicar su Capítulo IV a las Instituciones de los Territorios Históricos.

También se refiere a los Territorios Históricos la Ley 7/1985, de 2 de abril, Reguladora de las Bases de Régimen Local, en concreto su artículo 39 señala esto:

«Los órganos forales de Álava, Guipúzcoa y Vizcaya conservan su régimen peculiar en el marco del Estatuto de Autonomía del País Vasco. No obstante, las disposiciones de la presente Ley les serán de aplicación con carácter supletorio».

Asimismo resulta de importancia lo dispuesto en la disposición adicional segunda de la citada Ley de Bases, que, además de otras previsiones de interés, señala lo siguiente en su apartado segundo:

«Los territorios históricos de Álava, Guipúzcoa y Vizcaya ejercerán las competencias que les atribuyen el Estatuto Vasco y la legislación interna de la comunidad autónoma que se dicte en su desarrollo y aplicación, así como las que la presente ley asigna con carácter general a las Diputaciones provinciales».

La dualidad de los Territorios Históricos tiene un claro reflejo en este precepto, que nos aclara que los Territorios Históricos van a ejercer dos tipos de competencias, por un lado, las que se atribuyen con carácter general a las Diputaciones Provinciales, que podríamos denominar competencias de régimen común; y, por otro lado, las competencias atribuidas por el Estatuto de Autonomía Vasco y la legislación interna de la Comunidad Autónoma que se dicte en su desarrollo y aplicación, que podríamos denominar competencias de régimen foral.

El Estatuto de Autonomía del País Vasco se limita a señalar una serie de materias que necesariamente habrán de constituir competencias exclusivas de los Territorios Históricos, de tal manera que el resto habrá de determinarse por la legislación autonómica vasca.

Esta legislación viene constituida, fundamentalmente, por la Ley del Parlamento Vasco de 25 de noviembre de 1983, de Relaciones entre las Instituciones Comunes de la Comunidad Autónoma del País Vasco y los Órganos Forales de sus Territorios Históricos, que al tiempo que establece una cláusula residual de competencias a favor de las instituciones comunes (artículo 6.1), establece un cuadro competencial (artículo 7) a favor de los Territorios Históricos que distingue entre competencias exclusivas, competencias de desarrollo y ejecución y competencias de ejecución.

Por su parte, la citada Ley aclara que, en las materias que sean de la competencia exclusiva de los Territorios Históricos, les corresponde a éstos las siguientes potestades: a) normativa, aplicándose las normas emanadas de sus 
Órganos Forales con preferencia a cualesquiera otras; b) reglamentaria; c) administrativa, incluida la inspección y d) revisora en la vía administrativa. En las materias en las que les corresponda el desarrollo normativo y la ejecución tendrán las siguientes potestades: a) de desarrollo normativo de las normas emanadas de las Instituciones Comunes, al no poder ir en contra de lo dispuesto en ellas las normas emanadas de los Órganos forales; b) reglamentaria; c) administrativa, incluida la inspección y d) revisora en la vía administrativa. Finalmente, en las materias en que correspondan la ejecución, les corresponden las siguientes potestades: a) reglamentaria, para la organización de sus propios servicios; b) administrativa, incluida la inspección y c) revisora en la vía administrativa.

\section{LA COMISIÓN ARBITRAL}

Como puede apreciarse, resulta evidente la complejidad del proceso de actualización de los derechos históricos legitimado por la Constitución, llevado a cabo por el Estatuto de Autonomía y completado por la Ley del Parlamento Vasco antes aludida; como igualmente complejo resulta el reparto competencial que se opera entre las instituciones comunes de la Comunidad Autónoma y los órganos forales de los Territorios Históricos y la propia arquitectura competencial de estos últimos, lo que motiva la previsión contenida en el artículo 39 del Estatuto, que dispone la existencia de una Comisión Arbitral que resolverá los conflictos de competencia que se puedan suscitar entre las Instituciones de la Comunidad Autónoma y las de cada uno de sus Territorios Históricos; Comisión que va a estar formada por un número igual de representantes designados libremente por el Gobierno Vasco y por la Diputación Foral del Territorio interesado y presidida por el Presidente del Tribunal Superior de Justicia del País Vasco.

Debe ponerse de manifiesto asimismo la inexistencia de control jurisdiccional sobre las decisiones y resoluciones de dicha Comisión ${ }^{5}$ (disposición adicional primera, apartado segundo, de la Ley 29/1998, de 13 de julio, Reguladora de la Jurisdicción Contencioso-Administrativa).

\footnotetext{
${ }^{5}$ Obviamente nos referimos a sus decisiones y resoluciones en el ejercicio de su función delimitadora o, mejor dicho, clarificadora de competencias, sin perjuicio del control jurisdiccional de su actuación como órgano puramente administrativo (actos relativos a su personal, contratación, etc.).
} 


\section{IV. ÓRGANOS FORALES}

\section{Juntas Generales. Naturaleza jurídica de las normas dictadas por las Juntas Generales}

Las Juntas Generales de los Territorios Históricos constituyen un órgano representativo elegido directamente, son titulares de la potestad normativa y de la competencia para elegir al Diputado general, aprobar los presupuestos y controlar la acción de la Diputación Foral.

Uno de los problemas centrales que ha planteado el enjuiciamiento de la actividad de los Territorios Históricos ha sido el intentar determinar la naturaleza jurídica de las normas dictadas por sus Juntas Generales y si éstas gozan del valor de ley. El problema se ha planteado por diversas razones; la primera de ellas ha sido la percepción de las Juntas Generales como unos órganos que resultan idénticos en su composición, estructura y funcionamiento a cualquier asamblea legislativa de una Comunidad Autónoma o incluso al Parlamento Central ${ }^{6}$, configurándose así como el «Parlamento peculiar de un Territorio Histórico».

En segundo lugar, hemos de recordar que el artículo 8.1 de la Ley de Relaciones entre las Instituciones Comunes de la Comunidad Autónoma del País Vasco y los Órganos Forales de sus Territorios Históricos, señala que en las materias que sean de la competencia exclusiva de éstos, las normas emanadas de sus órganos forales se aplicarán con preferencia a cualesquiera otras. Si bien, junto con lo anterior, se atribuye exclusivamente al Parlamento Vasco (artículo 6.2 de la citada Ley) la facultad de dictar normas con rango de ley.

Por su parte, la Ley 4/1999, de 13 de enero, de modificación de la Ley 30/1992, de 26 de noviembre, de Régimen Jurídico de las Administraciones Públicas y del Procedimiento Administrativo Común, incorpora una disposición adicional decimosexta que dispone que «En la Comunidad Autónoma del País Vasco, a efectos de lo dispuesto en el artículo segundo, se entenderá por Administraciones públicas las Diputaciones Forales y las Administraciones institucionales de ellas dependientes, así como las Juntas Generales de los Territorios Históricos en cuanto dicten actos y disposiciones en materia de personal y gestión patrimonial sujetos al derecho público».

Al mismo tiempo, la disposición adicional primera, apartado primero, de la Ley 29/1998, de 13 de julio, Reguladora de la Jurisdicción ContenciosoAdministrativo, por lo que ahora nos interesa, señala que «En la Comunidad Autónoma del País Vasco (...) la referencia del apartado 3, letra a), del ar-

${ }^{6}$ Vid. una amplia explicación de la controversia en J. M. CASTELl ARTECHE, «La problemática jurídica actual de los Territorios Históricos vascos», Revista de Estudios de la Administración Local y Autonómica, número 291, 2003, págs. 236 y ss. 
tículo 1 incluye los actos y disposiciones en materia de personal y gestión patrimonial sujetos al derecho público adoptados por los órganos competentes de las Juntas Generales de los Territorios Históricos».

Es evidente que estas normas dibujan una cierta asimilación de las actuaciones de las Juntas Generales a las asambleas legislativas. Ahora bien, la enmienda que pretendía que las normas forales estuvieran sometidas únicamente al control de constitucionalidad del Tribunal Constitucional y que dicho Tribunal fuera el competente para resolver los conflictos que se plantearan entre la Administración del Estado y los Territorios Históricos, no vio finalmente la luz; de tal manera que los intentos de explicar la naturaleza de tales normas como disposiciones materialmente legislativas o como reglamentos autónomos derivados directamente del Estatuto de Autonomía que define las competencias exclusivas de los Territorios Históricos estableciendo una especie de reserva reglamentaria a favor de éstos, no pueden evitar el control de tales normas por parte de la jurisdicción contencioso-administrativa, tal y como ha señalado la Sala Tercera del Tribunal Supremo (Sección Segunda) en su Sentencia de 20 de diciembre de 2004 (recurso de casación n. $\left.{ }^{\circ} 6745 / 1999\right)$.

En consecuencia, la fiscalización de las normas forales emanadas de las Juntas Generales no corresponderá al Tribunal Constitucional, sino a la jurisdicción contencioso-administrativa y, en concreto, ex artículo 10.1.b) de la Ley Jurisdiccional, a la Sala de lo Contencioso-Administrativo del Tribunal Superior de Justicia del País Vasco.

\section{Diputaciones Forales}

Las Diputaciones Forales son el órgano ejecutivo de los Territorios Históricos, órgano colegiado que asume el gobierno y la administración, correspondiéndole la función ejecutiva, la potestad reglamentaria y la iniciativa normativa. La Diputación Foral tiene como órganos cabecera el Consejo de Diputados, el Diputado General y los Diputados Forales.

En un primer momento, la Sala Tercera del Tribunal Supremo tuvo ocasión de abordar la cuestión de la competencia objetiva para el enjuiciamiento de las actuaciones de las Diputaciones Forales e indirectamente analizar su naturaleza jurídica en su Sentencia de 18 de mayo de 2004 (recurso de casación n. ${ }^{\circ}$ 6289/2000) con ocasión del análisis de la admisibilidad de un recurso de casación interpuesto contra una Sentencia del Tribunal Superior de Justicia del País Vasco que enjuició un recurso deducido frente a una actuación de la Diputación Foral de Guipúzcoa -en concreto, se impugnaba una Orden Foral del Departamento de Transportes y Carreteras de la Diputación Foral de Guipúzcoa, desestimatoria del recurso ordinario interpuesto frente a una Resolución del Director de Transportes por la que se denegaba la autorización para la prestación de un servicio regular de transporte de uso especial-. 
En aquella ocasión se partía de la «peculiar naturaleza sustantiva y procesal de las Diputaciones Forales», señalando que «No cabe duda de que las Diputaciones Forales, como órganos ejecutivos de los Territorios Históricos, exceden el carácter de la Administración Local a que se refiere la letra c), ya que no pueden ser equiparadas a las Diputaciones provinciales comunes por cuanto sus competencias superan a las de éstas, ostentando algunas -de las que se predica su naturaleza foral- que en otras Comunidades Autónomas corresponden a las Administraciones autonómicas. Por contra, tampoco pueden ser asimiladas a las Administraciones de las Comunidades Autónomas aludidas en la letra b), cuyo correlato es la propia Administración de la Comunidad Autónoma del País Vasco».

Desde dicho planteamiento, la Sala centró su esfuerzo interpretativo en buscar un acomodo para las Diputaciones Forales dentro del listado de Administraciones a que se refiere el artículo 1.2 de la Ley Jurisdiccional, pues resultaba necesario, a los meros efectos de determinar qué órgano jurisdiccional debería conocer de los recursos deducidos frente a los actos o disposiciones emanadas de aquéllas, asimilarlas a alguno de los tipos de Administración Pública que contempla el último precepto señalado, optando por aquella que fuera más acorde con su naturaleza, argumentando lo siguiente:

«Siendo así que, en virtud de la referida Disposición Adicional Primera, apartado 1, primer inciso, de la Ley de la Jurisdicción, las Diputaciones Forales constituyen una Administración incluida en el listado del artículo 1.2 de la propia Ley procesal, debe dárseles a efectos competenciales el tratamiento que sea más acorde con su naturaleza, y éste es sin duda, habida cuenta de la imposibilidad de su equiparación con la Administración Local por ostentar competencias que exceden las propias de las Diputaciones comunes, el que la Ley atribuye a las Administraciones de las Comunidades Autónomas mencionadas en la letra b) de citado artículo 1.2 de la Ley de la Jurisdicción.

La equiparación de las Diputaciones Forales en cuanto al régimen de recursos a las Administraciones autonómicas obliga a considerar de aplicación al supuesto de autos lo prevenido en el artículo 8.3 de la Ley Jurisdiccional».

Es decir, en tal sentencia se equiparó, a efectos de fiscalización jurisdiccional, a las Diputaciones Forales con la Administración de las Comunidades Autónomas, si bien se remitía para su enjuiciamiento al artículo 8.3 de la Ley procesal, razonando a tal efecto que «responde a la realidad de las Diputaciones Forales y resulta obligada para evitar la contradicción que supondría que los actos de éstas -de ámbito territorial inferior al de la Comunidad Autónoma-, tuviesen un sistema de recursos que otorgase menos competencias a los Juzgados de lo Contencioso-Administrativo que los actos de las propias Administraciones Autonómicas». En definitiva, se producía una 
equiparación de las Diputaciones Forales con la Administración periférica de la Comunidad Autónoma del País Vasco a efectos de su control jurisdiccional contencioso-administrativo.

Este criterio tuvo continuidad, entre otras, en la Sentencia de 11 de octubre de 2004 (recurso de casación n. ${ }^{\circ}$ 3385/2001) así como en los Autos de 9 de junio de 2005 (recurso de casación n. ${ }^{\circ} 3859 / 2001$ ) y de 22 de septiembre de 2005 (recurso de casación n. $^{\circ}$ 3125/2004), resoluciones que equiparaban a las Diputaciones Forales, siempre a efectos procesales, con la Administración descentralizada de la Comunidad Autónoma, y así entienden aplicable el artículo 8.3 de la Ley Jurisdiccional, de tal manera que la competencia para el enjuiciamiento de los concretos actos administrativos a que se referían tales recursos correspondía a los Juzgados de lo Contencioso-Administrativo, con la consiguiente inadmisión del recurso de casación, de conformidad con la interpretación realizada por el Tribunal Supremo de la disposición transitoria primera de la Ley Jurisdiccional.

Ahora bien, tal criterio mostraba una serie de insuficiencias claras y no ofrecía una respuesta satisfactoria en todos los casos, no sólo desde el punto de vista procesal, sino desde el punto de vista ontológico. Ha de tenerse en cuenta que el mencionado criterio de la Sala Tercera que equipara a efectos de fiscalización jurisdiccional a las Diputaciones Forales con la Administración de las Comunidades Autónomas y remite para la determinación concreta del órgano jurisdiccional competente al artículo 8.3 de la Ley Jurisdiccional, no resultaba plenamente acorde con la «peculiar naturaleza» de las Diputaciones Forales, como órganos propios de los Territorios Históricos que asumen la responsabilidad del gobierno y la administración del respectivo Territorio Histórico, dentro del marco competencial atribuido por el Estatuto de Autonomía del País Vasco y por la Ley del Parlamento Vasco de 25 de noviembre de 1983, de Relaciones entre las Instituciones Comunes del País Vasco y los Órganos Forales de sus Territorios Históricos, cuya naturaleza jurídica se caracteriza por una dualidad derivada de la asunción de competencias de régimen común y de régimen foral.

Ello es así porque, tal y como dijimos con anterioridad, conforme a lo dispuesto en la disposición adicional segunda de la Ley 7/1985, de 2 de abril, Reguladora de las Bases de Régimen Local, los Territorios Históricos y, en consecuencia, sus órganos forales, van a ejercer las competencias que se atribuyen con carácter general a las Diputaciones Provinciales (competencias de régimen común); $y$, por otro lado, van a ejercer las competencias que les atribuyen el Estatuto Vasco y la legislación interna de la Comunidad Autónoma que se dicte en su desarrollo y aplicación (competencias de régimen foral); lo que explica la denominada dualidad de los Territorios Históricos de la que la doctrina se ha hecho eco y que, necesariamente, ha de afectar, no sólo a su naturaleza jurídica, sino también al control jurisdiccional de sus actos y disposiciones ante la falta de una determinación concreta sobre el órgano u 
órganos de la jurisdicción al que sea encomendada dicha tarea en la Ley de la Jurisdicción Contencioso-Administrativa.

De ahí que el Tribunal Supremo haya rectificado su anterior doctrina y haya alumbrado una nueva, cuyo primer pronunciamiento se contiene en el Auto de 15 de junio de 2006 (recurso de casación n. ${ }^{\circ}$ 9184/2003) que señala, en su fundamento jurídico quinto, lo siguiente:

«(...) habrá de atenderse a la naturaleza jurídica dual de los órganos forales o, lo que es lo mismo, a la naturaleza de las competencias ejercitadas en cada caso por tales órganos -de régimen común o foral- para asimilarlas, según el caso, a las Entidades locales o a las Comunidades Autónomas, a los efectos de proceder a la aplicación de los artículos 8 y 10 de la LRJCA.

Ante lo expuesto, cuando las Diputaciones Forales ejerzan competencias de «régimen común», esto es, las que la Ley 7/1985, de 2 de abril, Reguladora de las Bases de Régimen local, atribuye con carácter general a las Diputaciones Provinciales (disposición adicional segunda, apartado segundo, de dicha Ley), habrá de tomarse en consideración el artículo 8.1 de la Ley de la Jurisdicción Contencioso-Administrativa que atribuye a los Juzgados de lo ContenciosoAdministrativo el conocimiento de los recursos que se deduzcan frente a los actos de las Entidades locales, excluidas las impugnaciones de cualquier clase de instrumentos de planeamiento urbanístico (estas últimas se atribuirían a la Sala correspondiente del Tribunal Superior de Justicia), así como el artículo 10.1.b) que atribuye a dicha Sala el conocimiento de los recursos que se deduzcan contra las disposiciones generales de las Entidades locales.

Finalmente, cuando ejerzan competencias de «régimen foral», esto es, las que exceden de las propias de una Diputación Provincial y que en un territorio no foral corresponderían a las Comunidades Autónomas, habrán de tomarse en consideración los apartados segundo y tercero del artículo 8 de la Ley Jurisdiccional sin que puedan equipararse, no obstante, las Diputaciones Forales a la Administración periférica de las Comunidades Autónomas (...)».

No obstante, no siempre va a ser fácil la tarea de aislar la naturaleza común o foral de la competencia ejercitada en cada caso, razón por la cual se impone un análisis individualizado de cada supuesto. En el asunto al que se refiere el Auto de 15 de junio de 2006 al que nos acabamos de referir, habiéndose impugnado un instrumento de planeamiento urbanístico, se concluye, por lo que a nosotros nos interesa, con que la competencia corresponde a la Sala de lo Contencioso-Administrativo del Tribunal Superior de Justicia, razonándose de la siguiente manera:

«(...) versando el recurso contencioso-administrativo sobre la denegación de la aprobación definitiva de un instrumento de 
planeamiento, en concreto, de un plan especial, es evidente que se está ejercitando una competencia que excede de las propias de una Diputación Provincial y que la misma correspondería, en un territorio no foral, a la correspondiente Comunidad Autónoma. Por lo tanto, el enjuiciamiento de la misma, teniendo en cuenta la naturaleza de disposición de carácter general que conforme a reiterada jurisprudencia de esta Sala cabe predicar de los instrumentos de planeamiento, corresponde, en única instancia, a la Sala de lo Contencioso-Administrativo del Tribunal Superior de Justicia con arreglo al artículo 10.1.b) de la LRJCA, sin perjuicio del ulterior recurso de casación que, tal y como se infiere de lo dicho hasta ahora, ha de admitirse en el presente caso».

Por su parte, en el Auto de 21 de diciembre de 2006 (recurso de casación

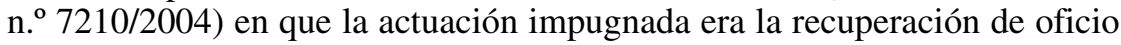
de un determinado bien por parte de la Diputación Foral de Guipúzcoa, se concluye que la competencia corresponde al Juzgado de lo ContenciosoAdministrativo, razonándose en el siguiente sentido:

«(...) versando el recurso contencioso-administrativo sobre la recuperación de oficio de un determinado bien (extremo este que no resulta controvertido por la Diputación Foral recurrente), resulta claro que en el presente supuesto la Administración está ejercitando una competencia que podemos catalogar claramente como de "régimen común" pues la potestad de recuperación de oficio de sus bienes constituye una potestad atribuida con carácter general a las Entidades locales territoriales ex artículo 4.1.d) de la Ley 7/1985, de 2 de abril, Reguladora de las Bases de Régimen Local, en relación con el artículo 82 de la citada Ley, sin que pueda considerarse, en consecuencia, que en este caso se exceden las competencias propias de una Diputación Provincial.

No cabe duda, por lo tanto, que el concreto acto administrativo recurrido en la instancia constituye una manifiestación de tal potestad de recuperación de oficio de sus bienes, que encuentra perfecto acomodo en el ámbito al que se refiere el artículo 8.1 de la Ley Jurisdiccional».

Se añade además, en el presente caso, lo siguiente:

«(...) la representación procesal de la Diputación Foral confunde la competencia exclusiva que el artículo 37.3.d) del Estatuto de Autonomía del País Vasco atribuye a las instituciones de los Territorios Históricos en materia de regulación del régimen de los bienes provinciales y municipales, tanto de dominio público como patrimoniales o de propios y comunales (competencia que ha sido ejercitada por las Juntas Generales de Guipúzcoa mediante la aproba- 
ción de la Norma Foral 8/1996, de 9 de julio, reguladora del Régimen Jurídico del Patrimonio del Territorio Histórico, competencia normativa que sí cabría conceptuar como "foral", al exceder las competencias propias de una Diputación Provincial), con la potestad de las que goza toda Entidad local territorial, Diputaciones Provinciales incluidas, para dictar actos administrativos a través de los cuales llevar a cabo la recuperación de oficio de sus bienes; potestad que cabe predicar de todas las Entidades locales territoriales, tal y como dijimos con anterioridad, en aplicación del artículo 4.1.d) de la Ley 7/1985, de 2 de abril, Reguladora de las Bases de Régimen Local.

Por lo tanto, lo determinante en el presente caso no es la naturaleza foral de la normativa que haya de aplicar la Administración para ejercer la potestad de recuperación de oficio, sino si dicha potestad puede predicarse con carácter general de toda Diputación Provincial, como sucede en el presente caso, o si, por el contrario, excede del ámbito propio de actuación de una Diputación de "régimen común"».

Otros supuestos que con los que ha tenido que enfrentarse la Sala Tercera del Tribunal Supremo y que contribuyen a clarificar criterios en la materia han sido los siguientes:

- Autos de 13 de julio y de 19 de octubre de 2006 (recursos de casación n. ${ }^{\circ} 3130 / 2004$ y $2725 / 2004$ ), de los que se deduce que la competencia para conocer de los recursos interpuestos contra las resoluciones dictadas por los Tribunales Económico-Administrativo Forales corresponde a la Sala de lo Contencioso-Administrativo del Tribunal Superior de Justicia del País Vasco. Ha de señalarse que a los Organismos Jurídico-Administrativo Forales les corresponde como órganos colegiados o Tribunales Económico-Administrativo Forales la revisión en vía económico-administrativa de los actos de esa naturaleza de las Diputación Forales y de sus Organismos Autónomos. Aunque es evidente que tales Organismos no constituyen un órgano económicoadministrativo de la Hacienda estatal, sino de la foral, las peculiaridades de esta última y la ausencia de una previsión de atribución competencial expresa obligó al Tribunal Supremo a buscar el mejor encuadramiento que se acomodara a la compleja naturaleza jurídica de la Administración autora del acto y ese encuadramiento, en opinión de la Sala Tercera, es la Sala de lo Contencioso-Administrativo del Tribunal Superior de Justicia por la vía del artículo 10.1.d) de la Ley Jurisdiccional.

- Auto de 29 de marzo de 2007 (recurso de casación n. ${ }^{\circ}$ 625/2006) que califica como competencia de régimen común y, en consecuencia, considera de la competencia de los Juzgados de lo Contencioso-Adminis- 
trativo, la aprobación de la certificación final de obras de un Proyecto de Abastecimiento de Aguas, señalándose al respecto lo siguiente: «(...) con independencia de la potestad para la contratación que puede predicarse de las Entidades locales conforme al artículo 88 de la Ley 7/1985, de 2 de abril, Reguladora de las Bases de Régimen Local, ha de significarse igualmente que la materia objeto del contrato administrativo (abastecimiento de agua) constituye una de las materias típicas de competencia municipal (artículos 25.2.1) y 26.1.a) de la Ley de Bases de Régimen Local), constituyendo, además un servicio municipal obligatorio. Por otro lado, ha de tenerse en cuenta la competencia de las Diputaciones Provinciales para la cooperación a las obras y servicios de competencia municipal (artículo 36 de la Ley de Bases) que, además, según especifica el artículo 26.3 de la citada norma, habrá de dirigirse preferentemente al establecimiento y adecuada prestación de los servicios municipales obligatorios, entre los que se encuentra, como ya se ha dicho, el abastecimiento de agua, debiendo asegurar, asimismo, el acceso de la población de la provincia al conjunto de los servicios mínimos de competencia municipal». En parecidos términos y respecto de la contratación administrativa se pronuncia el Auto de 26 de abril de 2007 (recurso de casación n. ${ }^{\circ}$ 4624/2005).

- Auto de 29 de marzo de 2007 (recurso de casación n. ${ }^{\circ}$ 7222/2005) que califica igualmente como competencia de régimen común y, en consecuencia, considera de la competencia de los Juzgados de lo Contencioso-Administrativo, el proceso selectivo llevado a cabo por la Diputación Foral de Guipúzcoa para la cobertura de tres plazas de Técnico Medio Forestal. Se razona por parte del Tribunal Supremo en el siguiente sentido: «(...) versando el recurso contencioso-administrativo sobre la resolución de un proceso selectivo para la cobertura de tres plazas de Técnico Medio Forestal, resulta claro que en el presente supuesto la Administración está ejercitando una competencia que podemos catalogar claramente como de «régimen común» pues la selección del personal de la correspondiente Corporación, ya sea funcionario o laboral, constituye una facultad atribuida con carácter general a todas las Entidades locales ex artículo 91 de la Ley 7/1985, de 2 de abril, Reguladora de las Bases de Régimen Local, derivada de su propia potestad de autoorganización (artículo 4.1.a) de la citada Ley), sin que pueda considerarse, en consecuencia, que en este caso se exceden las competencias propias de una Diputación Provincial (...) por otro lado, pese a los esfuerzos dialécticos desplegados por la citada representación procesal por encontrar un acomodo "foral" en los cometidos desarrollados por un Técnico Medio Forestal, lo cierto es que el artículo 84 del Texto Refundido de las disposiciones legales vigentes en materia de Régimen Local atribuye, sin ningún genero de dudas, competencias a los Entes locales para la conservación y mejora 
de los montes, competencias a las que igualmente hace mención la Sentencia de esta Sala de 22 de noviembre de 2001 (recurso de casación n. ${ }^{\circ}$ 1977/1995), de tal manera que no puede sostenerse que la provisión de tres plazas de Técnico Medio Forestal excedan de las propias de una Diputación Provincial».

- Auto de 28 de junio de 2007 (recurso de casación n. ${ }^{\circ}$ 727/2006) que subraya la posible afectación de intereses de índole foral para considerar que la competencia para conocer de la desatención por parte de la Diputación Foral de Vizcaya al requerimiento formulado por la Administración General del Estado para que diera cumplimiento a la legislación sobre banderas, corresponde a la Sala de lo ContenciosoAdministrativo del Tribunal Superior de Justicia del País Vasco.

- Auto de 27 de septiembre de 2007 (recurso de casación n. ${ }^{\circ}$ 630/2006) que califica como competencia de régimen común y, en consecuencia, considera de la competencia de los Juzgados de lo Contencioso-Administrativo, el Acuerdo del Consejo de Diputados de la Diputación Foral de Guipúzcoa por el que se acuerda el ejercicio de acciones judiciales en reclamación de los daños y perjuicios derivados de la catástrofe del buque «Prestige».

En definitiva, como puede observarse la complejidad del proceso de actualización de los derechos históricos ha dado lugar a entidades que quedan imbuidas de dicha complejidad en su propia naturaleza jurídica y que si bien participan de la consideración de entidades locales y en cuanto tal ejercitan competencias de «régimen común», también ejercitan otras de «régimen foral» que las singularizan; lo que va a afectar incluso a su régimen de fiscalización jurisdiccional, tal y como hemos pretendido reflejar, si bien de forma esquemática, en este estudio. 